\title{
PLANT GENOTYPE AND ENVIRONMENT INTERACT TO SHAPE A DIVERSE ARTHROPOD COMMUNITY ON EVENING PRIMROSE (OENOTHERA BIENNIS)
}

\author{
Marc T. J. Johnson ${ }^{1}$ And Anurag A. Agrawal ${ }^{2}$ \\ Department of Botany, University of Toronto, Toronto, Ontario M5S 3B2, Canada
}

\begin{abstract}
Both an individual's genotype and environment govern its phenotype, and this phenotype may have extended consequences for species interactions and communities. We examined the importance of plant genotype and environmental factors operating at large (habitat) and small (microhabitat) spatial scales in affecting a multitrophic arthropod community on plants. We planted 926 plants from 14 genotypes of Oenothera biennis into five natural habitats that represent the range of environments in which this plant locally occurs. Genotypic differences among plants accounted for as much as $41 \%$ of the variation in arthropod diversity (Simpson's diversity index) and also affected arthropod evenness, richness, abundance, and biomass on individual plants. However, the effects of particular plant genotypes on the arthropod community varied across habitats (i.e., there were significant plant genotype-by-habitat interactions). Plant genotype explained more variation in the arthropod community than did environmental variation among microhabitats, but less variation than habitats, as predicted by the scale-dependent hypothesis. Herbivores and omnivores were more strongly affected by plant genetic variation than predators, consistent with the notion that phytophagous insects undergo stronger reciprocal interactions with plants than do predators. We detected heritable variation in arthropod community variables and the ability for the herbivore community to select on plant traits, suggesting that evolution in $O$. biennis can lead to changes in the arthropod community. Genetic variation in plant size, architecture, and reproductive phenology were the plant traits most strongly correlated with arthropod community variables. Our results demonstrate that genotype-by-environment interactions are a major determinant of arthropod community structure.
\end{abstract}

Key words: biodiversity; community evolution; community genetics; community structure; extended phenotype; genetic variation; genotype-by-environment interaction; herbivory; Oenothera biennis; plant-insect interactions; plant resistance; spatial scale.

\section{INTRODUCTION}

The phenotypes of all organisms are determined by their genotype, the environment, and their interaction $(\mathrm{G} \times \mathrm{E})$. Phenotypic variation may have extended consequences for species interactions and ultimately community structure. For example, genetic and environmental influences on plant traits can influence the abundance and distribution of individual herbivore populations (Fritz and Simms 1992). If these effects scale up to structure entire communities, then an examination of $\mathrm{G} \times \mathrm{E}$ may be critical to understanding community ecology. Several authors have recently advocated such a "community genetics" approach (Antonovics 1992, Neuhauser et al. 2003, Whitham et al. 2003). In this paper, we examined the community genetics of plantarthropod interactions to understand how plant genotype and the environment concurrently shape a multitrophic arthropod community. Although environmen-

Manuscript received 6 July 2004; revised 20 September 2004; accepted 28 September 2004. Corresponding Editor: C. W. Fox.

${ }^{1}$ E-mail: johnson@botany.utoronto.ca

2 Present address: Department of Ecology and Evolutionary Biology, Corson Hall, Cornell University, Ithaca, New York 14853 USA. tal variation has long been recognized as an important factor structuring communities (Andrewartha and Birch 1954), the potential for intraspecific genetic variation in plants to affect the diversity and abundance of arthropods has been recognized relatively recently (Fritz 1992). Genetic variation in plant resistance can strongly impact individual herbivore populations (Da Costa and Jones 1971, Karban 1992, Underwood and Rausher 2000), and there is some evidence that plant genotype can affect the abundance of suites of herbivores (Maddox and Root 1987, Fritz and Price 1988), as well as the structure of these communities (Fritz and Price 1988, Maddox and Root 1990). The effects of genetic variation on arthropods have been best studied in interspecific hybrid systems, where different hybrid types (i.e., parental species vs. $F_{1}, F_{2}$, and backcrossed hybrids) can shape the diversity and abundance of large arthropod communities on trees (Dungey et al. 2000, Fritz et al. 2003, Hochwender and Fritz 2004).

To understand the importance of plant phenotypic variation for arthropod communities, it is necessary to determine the relative effects of plant genotype and the environment, as well as to disentangle the interactions between these factors. Although controlled experi- 
ments have shown that genetic and environmental factors can interact to affect arthropod populations (e.g., Maddox and Cappuccino 1986), the relative importance of these two factors in nature, as well as the conditions under which they interact, are unclear (Fritz 1990, Strauss 1990, Stiling 1994). Incorporating spatial scale into such studies is likely to provide novel insight into the interplay between these factors (Stratton and Bennington 1998). Specifically, biotic factors (e.g., genetic variation) are predicted to be more important in structuring communities over small spatial scales, while abiotic factors will take precedence over larger spatial scales (scale-dependent hypothesis; Menge and Olson 1990, Jackson et al. 2001). This hypothesis is based on the fact that environmental variance monotonically increases with increasing spatial scale (Bell 1992).

The impact of plant phenotypic variation on arthropod communities is likely to vary with the trophic position of species. For example, plants directly and indirectly interact with both primary (i.e., herbivores) and secondary (i.e., predators and parasitoids) consumers, and the effects of plant variation on these two groups may not be concordant. Intuitively, we expect plant phenotype to have the strongest impact on herbivores and omnivores, as phytophagous arthropods directly consume plant tissue. This prediction is supported by the widespread occurrence of genetic variation in plant resistance to herbivory (Fritz and Simms 1992) and the expectation that phytophagous insects have undergone a long evolutionary history with their plant hosts (Farrell 1998). In contrast, phenotypic variation is predicted to have a weaker effect on the third trophic level, as plant traits specific to attracting or deterring predators and parasitoids are relatively fewer (Vinson 1999, Rudgers 2004). Instead, the effects of plants on predators may frequently be mediated by variation in herbivore population size (Fritz 1995).

To examine the relative importance of plant genotype vs. environmental factors in influencing a diverse tritrophic arthropod community, we tested several specific hypotheses. First, we tested the scale-dependent hypothesis. We expected that plant genotype would be more important than environmental variation in shaping the arthropod community over small spatial scales (within habitats) and less important over larger spatial scales (between habitats). Second, we predicted that phytophagous arthropods (i.e., herbivores and omnivores) would be more strongly affected by genetic variation in plants than predators. Third, we investigated potential mechanisms behind the observed community patterns using correlations between genetically variable plant traits and arthropod community variables. Lastly, we tested the community evolution hypothesis (Whitham et al. 2003). The study of the communitylevel consequences of phenotypic variation in plants has lead to the proposition that evolution in plant populations may extend to shape the structure of arthropod communities. Whitham et al. (2003) proposed this hy- pothesis based on the premise that the composition of arthropod communities can be a heritable component of the plant. We investigated this idea by measuring the heritability of arthropod community variables and the potential for a community of herbivores to select on plant resistance.

\section{Methods \\ Study site and system}

Experiments were conducted in southern Ontario, Canada, at the Koffler Scientific Reserve at Jokers Hill (Jokers Hill). Jokers Hill is a 350-ha field station owned by the University of Toronto, located $50 \mathrm{~km}$ north of Toronto, Ontario $\left(44^{\circ} 03^{\prime} \mathrm{N}, 79^{\circ} 29^{\prime} \mathrm{W}, 300 \mathrm{~m}\right.$ above sea level; information available online). ${ }^{3}$

Evening primrose, Oenothera biennis L. (Onagraceae), is a native, facultative biennial that forms a single basal rosette before bolting into a $0.5-2.5 \mathrm{~m}$ flowering stalk (see Plate 1). It commonly forms discrete patches of plants in open habitats at Jokers Hill, particularly in old fields, mowed lawns, and recently disturbed soil. Oenothera biennis primarily self-pollinates to produce clonal seeds, which is a function of its permanent translocative heterozygote genetic system (Cleland 1972). Permanent heterozygotes have nonhomologous chromosome sets that rarely recombine during meiosis, but instead match-up the same nonhomologous chromosome sets as the parent to form clonally related zygotes (Cleland 1972). This genetic behavior provides a powerful ecological tool because numerous replicates of single clonal genotypes can be grown from seed. The predominately self-fertilizing behavior of $O$. biennis is commonly employed by plants and makes circumscribing populations difficult because of the lack of gene flow within and between populations. We propose that each discrete patch of $O$. biennis plants, which typically consists of a single genotype (Levin 1975), could be considered a population.

The arthropod community associated with $O$. biennis is both large and diverse (Dickerson and Weiss 1920, Kinsman 1982), making this multitrophic system an ideal one to understand the effects of phenotypic variation on the diversity and structure of higher trophic communities. In an extensive survey of insects on $O$. biennis in New Jersey, USA, Dickerson and Weiss (1920) recorded 110 insect species: $34 \%$ were herbivores, $10 \%$ were pollinators, and the remaining $56 \%$ were composed of predators, inquilines, and transient visitors. Kinsman (1982) observed 41 insect taxa in upstate New York, USA, eight of which specialized on the Oenothera genus.

\section{Common-garden experiment}

We collected seeds of 14 clonal families (hereafter genotypes) from 11 discrete patches of O. biennis at Jokers Hill, one patch in Toronto $(50 \mathrm{~km}$ south of Jokers

\footnotetext{
${ }^{3}\langle$ www.200.utoronto.ca/jokershill〉
} 

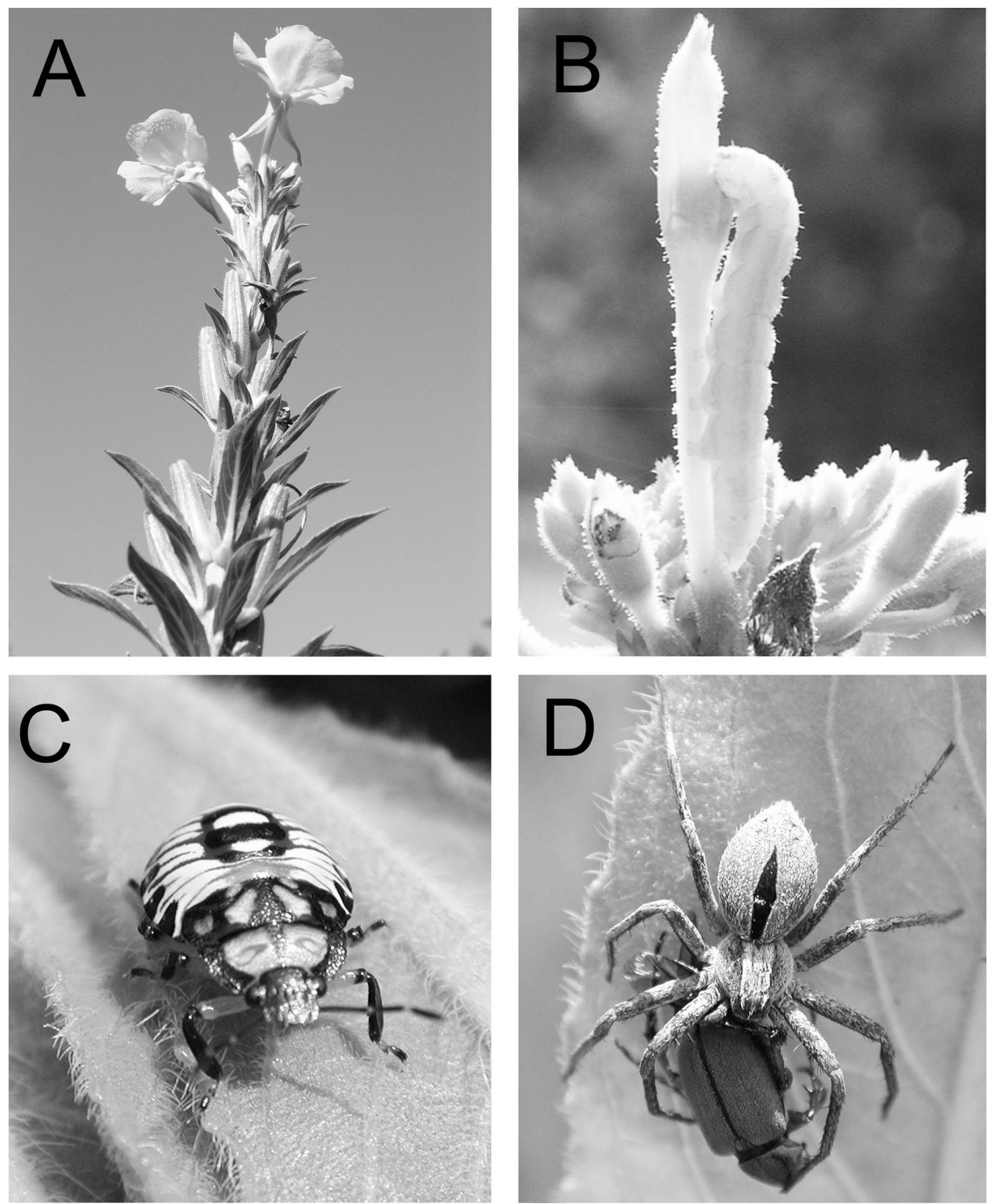

Plate 1. (A) The plant used in the study, Oenothera biennis, and (B-D) representative arthropods. Arthropods depicted are (B) Schinia florida, a specialist lepidopteran herbivore, (C) Podisus maculiventris (fourth-instar nymph), an hempiteran omnivore, and (D) a spider (Thanatus sp., Philodromidae) carrying a freshly killed Macrodactylus subspinosus (rose chafer) in its fangs. Photo credits: M. Johnson.

Hill), and one in Mississauga (50 km southwest). The discrete patches at Jokers Hill were separated by $0.1-$ $3.5 \mathrm{~km}$ and two of the 12 unique genotypes were collected from a single site at Jokers Hill. In late March 2002, we germinated seeds from each genotype within petri dishes exposed to natural sunlight. We then randomized seedlings individually into $250-\mathrm{mL}$ pots containing soil (Promix General Purpose BX soil; Premier Horticulture, Dorval, Quebec, Canada). In total, there were 926 plants, comprising 64-67 replicate plants per genotype. We sprayed the soil with liquid fertilizer (20: 20:20 N:P:K; $1 \mathrm{~g} / \mathrm{L}$ ) before and 2 wk following planting and added $0.25 \mathrm{~g}$ of slow-release Nutricote pellets (13: 13:13, N:P:K; Vicksburg Chemical, Vicksburg, Mississippi, USA) to the soil surface. We grew plants for $5 \mathrm{wk}$ in a greenhouse set at $25^{\circ} \mathrm{C}$, supplemented with 400-W high pressure sodium lights on a 14:10 h (day: night) cycle. We then moved plants outside to Jokers Hill in early May, at which time we transplanted plants into 500-mL pots. In early May, we found evidence for genetic differences between all genotypes by comparing six rosette traits (number of leaves; width, length, and distance from the leaf base to the widest point of the longest leaf; rosette width; and number of antho- 
cyanin pigmentation dots) using multivariate analysis of variance (M. T. J. Johnson, unpublished data).

In the third week of May, we transplanted all plants into five $15 \times 13 \mathrm{~m}$ common gardens (habitats) at Jokers Hill, which were separated by $0.6-2.8 \mathrm{~km}$. We selected the five habitats to represent the range in which O. biennis is locally found: a "mesic" old field; a "sandy" field with invading pine trees; a "xeric" old field; a freshly abandoned "mowed" lawn; and a freshly plowed "disturbed" field. Around each common garden we planted a one-plant-wide border of Oenothera to reduce edge effects. To study the effects of smallscale environmental variation, we divided each habitat into four equally sized contiguous spatial blocks (hereafter microhabitats), into which all genotypes were randomized. Within each habitat we measured soil moisture, soil composition, and vegetation density and diversity and found these variables to vary among microhabitats (M. T. J. Johnson and A. A. Agrawal, unpublished data). The importance of these specific variables for arthropod communities will be investigated in a future paper. In total there were five habitats, four microhabitats per habitat, and 14 plant genotypes, and each genotype was replicated with 3-4 plants per microhabitat.

We surveyed naturally colonizing arthropods on each plant six times between early June and mid-September. In sum, we counted 20500 individuals from 129 arthropod taxa comprised of herbivorous (46), omnivorous (14), and predatory (69) species. Arthropods were surveyed by looking over the entire plant, thus each plant received equal sampling effort with respect to its size. A third of taxa were identified to species, which confirmed the accuracy of our morphospecies definition. We did not sample several endophytic herbivore and parasitoid species, nor pollinators and pollen herbivores (e.g., bees and thrips). So that individuals were not counted twice between sampling dates, we took the maximum abundance for each arthropod species from each plant across all sampling dates. This approach provided a conservative estimate of the total number of individuals of each species that occurred on individual plants through the summer. Biomass was measured for the 52 most common species (we did not weigh any species that made up $<0.1 \%$ of the experiment-wide abundance) by drying specimens at $60^{\circ} \mathrm{C}$ and weighing $1-45$ individuals $(6.7 \pm 1.1$ individuals; mean $\pm 1 \mathrm{SE}$ ) per species. Arthropod diversity was calculated as the reciprocal of Simpson's diversity index $(D)$, which incorporates both the richness and evenness of species following $D=1 / \Sigma p_{i}^{2}$, where $p_{i}$ is the proportional abundance of a species, $i$. We characterized community evenness using Smith and Wilson's (1996) index $\left(E_{\mathrm{var}}\right)$, calculated as: $E_{\mathrm{var}}=1-2 / \pi\left(\arctan \left(\left(\Sigma \ln \left(a_{i}-x\right)^{2}\right) / R\right)\right)$, where $a_{i}$ is the abundance of the $i$ th species, $x=$ $\sum \ln \left(a_{i}\right) / R$, and $R$ is total arthropod richness on a given plant.
The effects of genotype, environment, and genotypeby-environment interactions were determined using restricted maximum likelihood (REML) with Proc Mixed of SAS version 8.02 (SAS Institute, Cary, North Carolina, USA) using the model: dependent variable = mean $_{\text {global }}+$ habitat + microhabitat[habitat] + genotype + genotype $\times$ habitat + genotype $\times$ microhabitat[habitat] + error. Square brackets indicate nested effects. Habitat was treated as a fixed effect because we objectively chose habitats to represent the range of habitats in which $O$. biennis locally occurs. The significance of this fixed effect was determined using an $F$ statistic where the degrees of freedom were approximated with the Satterthwaite method (Littell et al. 1996). We used the above model to estimate genotype and genotype $\times$ habitat broad-sense breeding values with best linear unbiased prediction (BLUP; Littell et al. 1996). BLUP estimates are analogous to but more accurate than genotype means because they use all available information and thus are less biased by dominance and environmental effects, as are genotype means (Shaw et al. 1995).

We calculated the percentage of the total variation explained in community variables by each factor (i.e., habitat, microhabitat, and genotype) using a completely random model. We estimated variance for microhabitat and genotypic effects within each habitat separately, using the model: dependent variable $=$ mean $_{\text {global }}+$ microhabitat + genotype + error, where all effects were random. We then used the estimates of the variance component from REML to calculate the percentage of variance explained by microhabitat and genotype in each habitat, followed by taking the mean across the five habitats.

Broad-sense heritabilities were calculated as $H^{2}=$ $V_{\mathrm{g}} / V_{\mathrm{T}}$ (Lynch and Walsh 1998), where $V_{\mathrm{g}}$ and $V_{\mathrm{T}}$ are the genetic and total components of variance, respectively. This equation is appropriate for $O$. biennis because it produces clonal progeny. Significance levels for heritabilities are from $Z$ tests of the genotype variance components in SAS Proc Mixed.

In quantitative genetic studies, maternal and common environmental effects can contribute to the variance attributed to genetic variation in plant resistance to arthropods (Agrawal 2002). We tried to reduce maternal effects by: (a) germinating all plants from seed simultaneously and (b) growing all plants randomized within a common environment for 2 mo before transplanting into the field. These methods should have effectively minimized maternal effects as the influence of seed size on $O$. biennis performance and maternally induced resistance are short lived following germination (Gross and Kromer 1986, Agrawal 2002).

\section{Measurement of plant traits}

We measured 14 plant traits to identify genetically variable phenotypic traits that could potentially correlate with community patterns. We measured early 


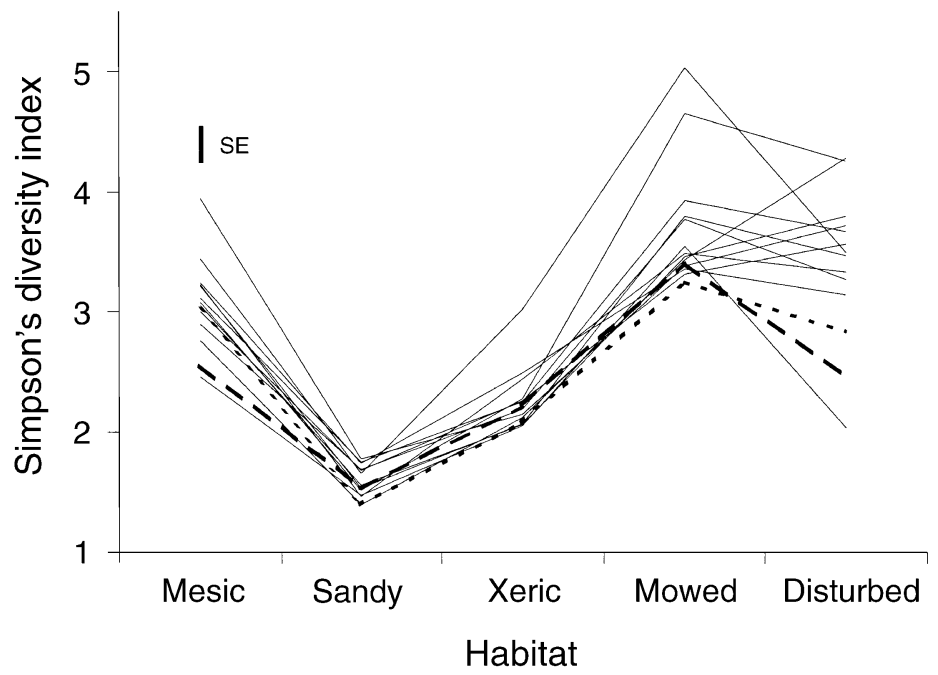

FIG. 1. The interaction between plant genotype and habitat for Simpson's diversity index of arthropods. This reaction norm plot shows multiple environments with lines connecting best linear unbiased predictors (BLUPs, analogous to mean values) for the 14 plant genotypes, and 1 SE of BLUPs is shown (SE was relatively constant). This figure illustrates crossover interactions in which genotypes supported the highest diversity of arthropods in one habitat and nearly the lowest in another. Interactions are also illustrated as nonsignificant variation between plant genotypes in some habitats (e.g., sandy) yet substantial genetic variation in others (e.g., disturbed; see Table 2). Dashed lines indicate the two genotypes collected outside Jokers Hill, from Mississauga (long dashes), and from Toronto, Ontario, Canada (short dashes). growth rate on all plants as rosette width (in centimeters) 2 wk following germination. Six weeks following germination we measured $10-15$ plants per genotype for rosette width again, number of leaves, and the number of anthocyanin pigmentation dots on leaves. We determined herbivore resistance using two methods. First, we quantified herbivory in early June by estimating the number of discrete damage holes caused by herbivores on two rosette leaves; the number of holes was well correlated with leaf area consumed $(r=0.95, P<0.001, N=39)$. Second, in July we excised a single leaf from each plant, placing the leaf on moist filter paper in a petri dish and allowing a single neonate caterpillar of Spodoptera exigua (a generalist herbivore) to feed for $6 \mathrm{~d}$. We recorded the mortality rate and the mass of surviving caterpillars. The use of $S$. exigua provides a measure of how physical and chemical resistance together affect the performance of a generalist herbivore, whereas the measure of herbivory described above would have been affected by both the preference and performance of herbivores. In July, we also measured a putative resistance trait, leaf toughness, as the grams of force required to penetrate the leaf surface using a force gauge penotrometer (Type 516; Chatillon, Kew Gardens, New York, USA).

We recorded which plants flowered in 2002 vs. 2003 in order to calculate flowering frequency for each genotype in 2002. All plants flowered in the disturbed habitat in 2002 and from these plants we measured five traits specific to reproductive plants: date of first flower, number of branches $>4 \mathrm{~cm}$ long, plant height (in centimeters), basal stem thickness (in millimeters), and lifetime biomass (in grams). Because these five traits were positively correlated (range of $r$ for genotype $\left[r_{\text {geno }}\right]=0.38-0.85 ; P<0.05$ in nine of 10 correlations $)$, we used principal components analysis (PCA) to reduce the data. Specifically, we used a correlation matrix extraction method with a minimum eigenvalue of 1 for extraction and the Varimax rotation procedure in Systat
(Systat Software, Richmond, California, USA; Tabachnick and Fidell 2001). The first axis explained 57\% of the variation in the five traits and was the only axis retained; all other axes had eigenvalues $<1$.

We used restricted maximum likelihood in Proc Mixed of SAS (SAS Institute) and the log likelihood ratio test (Littell et al. 1996) to determine whether the continuously varying traits genetically varied. For categorical responses (i.e., frequency of bolting/flowering, $S$. exigua mortality), we used a chi-squared test of independence to detect genetic variation. Genetic and phenotypic correlations among the traits and community variables were estimated with Pearson productmoment correlations.

\section{Effects of herbivores on plant fitness}

In 2003, we grew 133 O. biennis plants in a common garden adjacent to the mesic habitat garden. We covered plants with spun polyester bags and assigned herbivory to approximately half the plants by cutting 10 holes of $10 \mathrm{~cm}$ diameter in each bag, which provided arthropod access. Lifetime fitness was measured as the number of fruits. Seventeen unbagged plants were included as an overall control and measure of the effect of bags; there was no difference in fitness between bagged (with cut holes) and unbagged plants $\left(F_{1,71}=\right.$ $1.36, P=0.25)$, therefore we pooled these treatments.

\section{RESUlts}

Genotypes of $O$. biennis differed widely in their arthropod diversity as measured by Simpson's index (Fig. 1), species evenness, total species richness, total abundance, and biomass (Table 1). In all cases, the effect of plant genotype depended on the habitat in which plants grew (a significant genotype-by-habitat interaction), but very rarely did its effect depend on environmental variation between microhabitats (Table 1). Microhabitat variation consistently did, however, in- 
TABLE 1. Genetic and environmental effects on Simpson's diversity index, community evenness, total richness, total abundance, and total biomass of the arthropod community.

\begin{tabular}{|c|c|c|c|c|c|c|c|c|c|c|}
\hline \multirow[b]{2}{*}{ Factor } & \multicolumn{2}{|c|}{$\begin{array}{c}\text { Simpson's } \\
\text { diversity index }\end{array}$} & \multicolumn{2}{|c|}{ Evenness } & \multicolumn{2}{|c|}{ Total richness } & \multicolumn{2}{|c|}{ Total abundance } & \multicolumn{2}{|c|}{ Total biomass } \\
\hline & $\chi^{2} / F$ & $P$ & $\chi^{2} / F$ & $P$ & $\chi^{2} / F$ & $P$ & $\chi^{2} / F$ & $P$ & $\chi^{2} / F$ & $P$ \\
\hline Habitat (H) & 22.23 & $<\mathbf{0 . 0 0 1}$ & 45.34 & $<\mathbf{0 . 0 0 1}$ & 77.94 & $<\mathbf{0 . 0 0 1}$ & 27.84 & $<\mathbf{0 . 0 0 1}$ & 67.03 & $<\mathbf{0 . 0 0 1}$ \\
\hline Microhabitat (M)[H] & 25.7 & $<\mathbf{0 . 0 0 1}$ & 23.5 & $<\mathbf{0 . 0 0 1}$ & 9.8 & 0.001 & 69.5 & $<\mathbf{0 . 0 0 1}$ & 17.8 & $<\mathbf{0 . 0 0 1}$ \\
\hline Genotype (G) & 2.1 & 0.07 & 0 & $\ldots$ & 3.8 & 0.03 & 0 & $\ldots$ & 0.4 & 0.26 \\
\hline $\mathrm{G} \times \mathrm{H}$ & 32.1 & $<\mathbf{0 . 0 0 1}$ & 8.6 & 0.002 & 11.8 & $<\mathbf{0 . 0 0 1}$ & 93 & $<\mathbf{0 . 0 0 1}$ & 30.8 & $<\mathbf{0 . 0 0 1}$ \\
\hline $\mathrm{G} \times \mathrm{M}[\mathrm{H}]$ & 0.2 & 0.33 & 3.2 & 0.04 & 0.5 & 0.24 & 0.3 & 0.29 & 1.9 & 0.08 \\
\hline
\end{tabular}

Notes: $F$ values were calculated for the fixed effect (habitat), while $\chi^{2}$ values were calculated for the random effects (all other effects). $P$ values for the random effects were determined using restricted maximum likelihood and the log likelihood ratio test (Littell et al. 1996). Effects significant at $P<0.05$ are in boldface type. Squared brackets indicate nested effects, while dashes indicate undefined $P$ values for which the variance component was equal to 0 . For each variable we calculated $F$ statistics for the effect of habitat; all other effects used $\chi^{2}$ statistics with $1 \mathrm{df}$. The degrees of freedom for habitat are as follows: Simpson's diversity, 4, 28.2; evenness, 4, 20.3; total richness, 4, 24.6; total abundance, 4, 32.5; total biomass, 4, 30.3 .

dependently affect arthropod community composition (Table 1).

The effects of plant genotype and the interaction with habitat were not driven by the two genotypes collected outside Jokers Hill (from Toronto and Mississauga) (Figs. 1-4). For example, when we remove the two genotypes collected off Jokers Hill, a strong genotypeby-habitat interaction remains for Simpson's diversity index $\left(\chi_{1}=27.2, P<0.001\right)$ as do the effects of habitat
$\left(F_{4,29}=29.2, P<0.001\right)$ and microhabitat $\left(\chi_{1}=19.0\right.$, $P<0.001)$. This indicates that within $O$. biennis there is substantial genetic variation over relatively small spatial scales $(<4 \mathrm{~km})$.

Genotype-by-environment interactions were driven by two processes: (1) the proportion of the total variance in arthropod community composition explained by genotype (i.e., broad sense heritability, $H^{2}$ ), which was greater in some habitats than others (Table 2), and
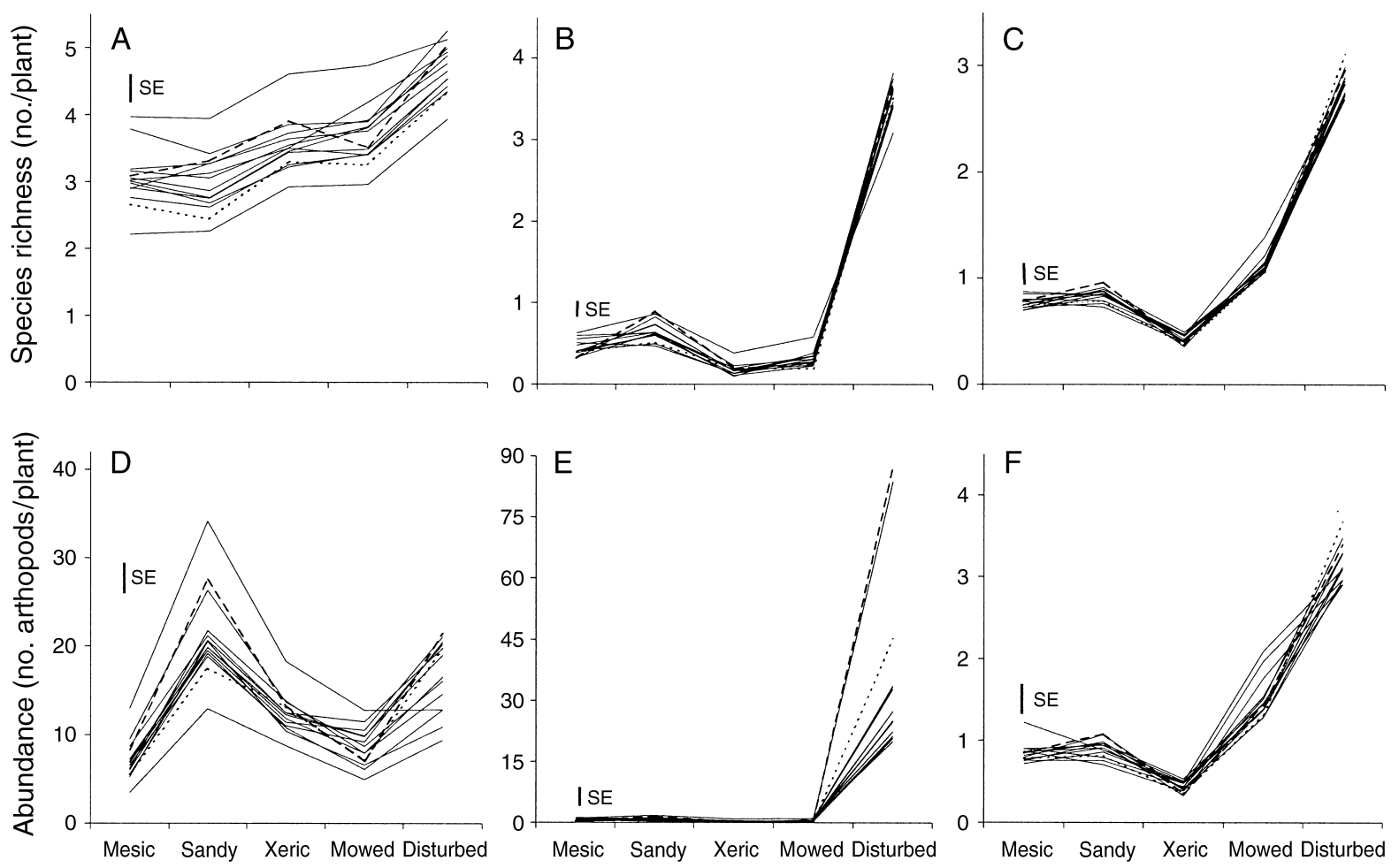

FIG. 2. The effects of plant genetic and habitat variation on arthropod species richness and abundance. We show species richness of (A) herbivores, (B) omnivores, and (C) predators, as well as abundance of (D) herbivores, (E) omnivores, and (F) predators. In each panel, axes are scaled to illustrate genotype-by-environment interactions. Lines connect the best linear unbiased predictors (BLUPs) of the 14 genotypes between habitats. Dashed lines indicate the two genotypes collected outside Jokers Hill, from Mississauga (long dashes), and from Toronto, Ontario, Canada (short dashes). 

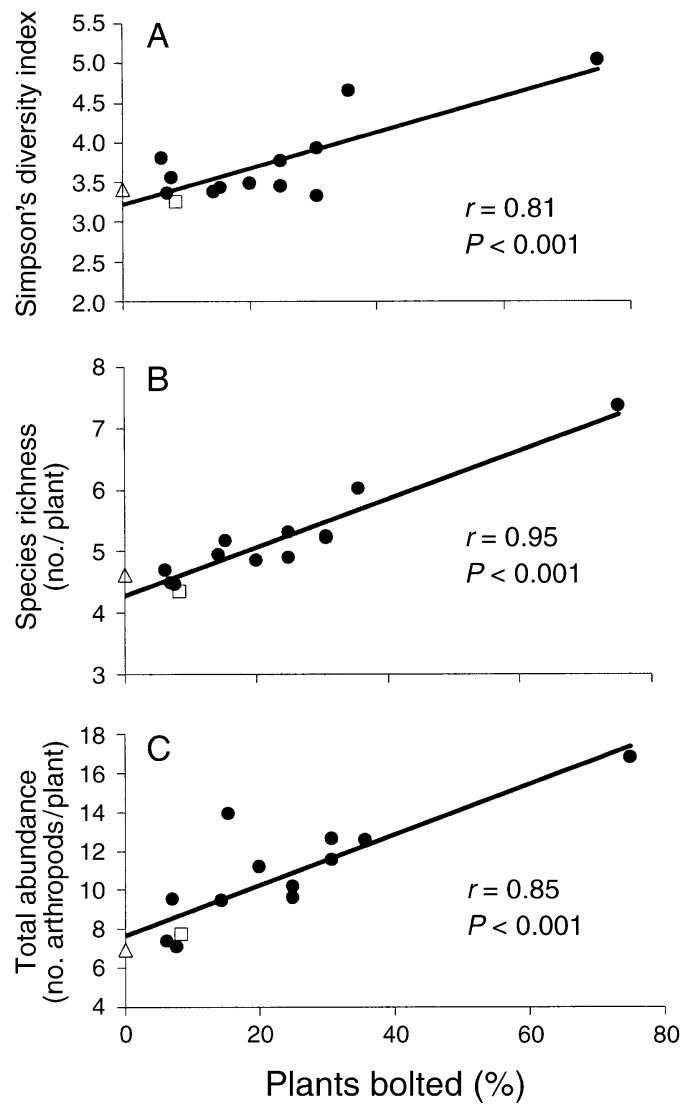

FIG. 3. Genetic correlations in the mowed habitat between bolting frequency and (A) Simpson's diversity index, (B) total arthropod richness, and (C) total arthropod abundance. One data point depicted by an open square and another by an open triangle represent the genotypes collected from Toronto and Mississauga, respectively.

(2) "crossover" effects, in which the rank order of plant genotypes changed between habitats (Appendix A) (Thomas and Bazzaz 1993). Both patterns are apparent for Simpson's index of arthropod diversity (Fig. 1), for which $H^{2}$ was low in some habitats and high in others (Table 2) and genotypes that supported high arthropod diversity in one habitat sometimes had low diversity in another (Fig. 1).

\section{Relative importance of plant genotype, habitat, and microhabitat}

When we compared the importance of genetic vs. large-scale (habitat) environmental variation, habitat had primacy, explaining $13-87 \%$ of variation in arthropod community variables. Within a habitat, genetic and microhabitat variation explained a mean of $8.2 \%$ and $5.6 \%$ of the variation among all community variables, respectively (Table 3 ), consistent with the scaledependent hypothesis (Menge and Olson 1990, Jackson et al. 2001) that the relative importance of plant genotype should be stronger at smaller compared to larger spatial scales. However, the effects of plant genotype varied among trophic levels (Table 3), with genotype explaining 1.2-2 times as much variation as microhabitat for herbivores and omnivores, while genotype and microhabitat explained equal variation for predators.

Consistent with our second prediction, plant genotypes strongly varied in herbivore species richness (Appendix B), with richness varying by as much as $79 \%$ between genotypes within a habitat (Fig. 2A). Plant genotype also affected omnivores (Fig. 2B), but not predators (Fig. 2C; Appendix B). We found similar results for the abundance of herbivores (Fig. 2D) and omnivores (Fig. 2E; Appendix B), with genotypes varying by as much as 3.7 -fold and 468 -fold, respectively. Plant genotype had a weak but significant effect on predator abundance (Fig. 2F; Appendix B), but the importance of plant genotype for predators appears to
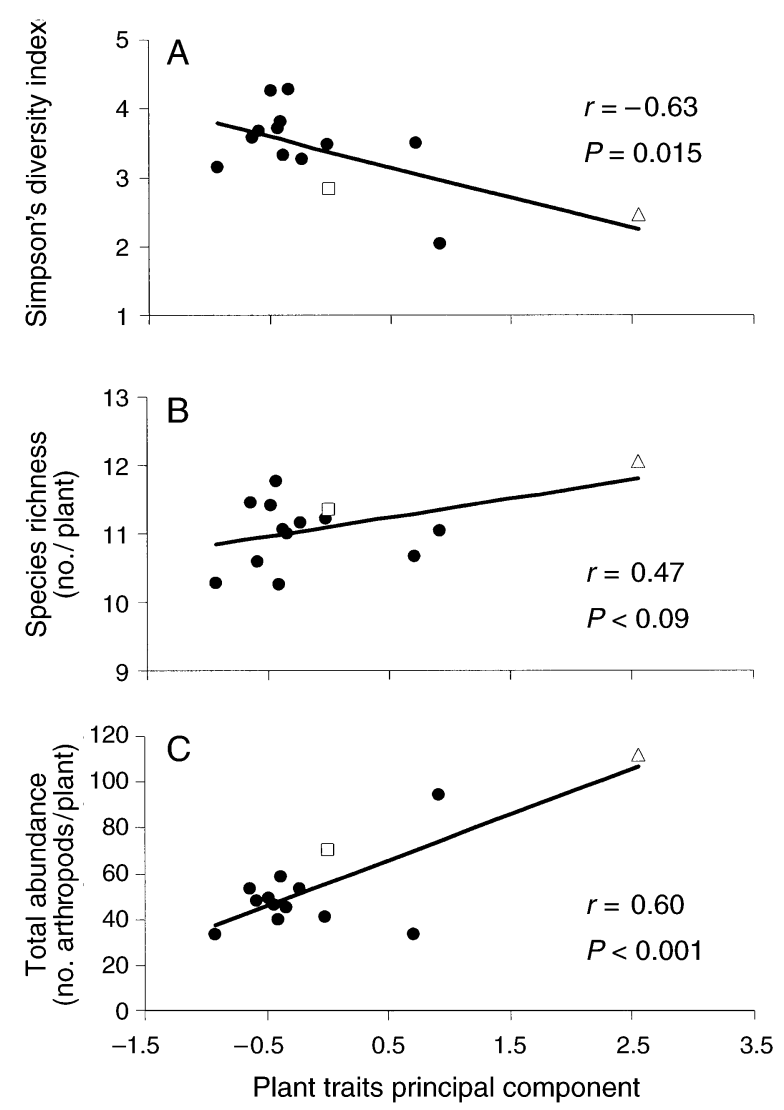

FIG. 4. Genetic correlations in the disturbed habitat between the plant traits principal component and (A) Simpson's diversity index, (B) total arthropod richness, and (C) total arthropod abundance. All plants flowered in the disturbed habitat, and the first principal component summarized 57\% of the variation in five traits specific to flowering plants (i.e., date of first flower, number of branches, plant height, basal stem thickness, and dry biomass). All traits positively loaded on this first axis and were thus positively correlated (see Methods). One data point depicted by an open square and another by an open triangle represent the genotypes collected from Toronto and Mississauga, respectively. 
TABLe 2. Broad-sense heritabilities $\left(H^{2}\right)$ of Simpson's diversity index, richness, and abundance of arthropods on Oenothera biennis in each habitat.

\begin{tabular}{lccccc}
\hline \hline \multicolumn{1}{c}{ Variable } & Mesic & Sandy & Xeric & Mowed & Disturbed \\
\hline Simpson's diversity index & 0.07 & 0.06 & 0.04 & $0.10 \dagger$ & $\mathbf{0 . 4 1}^{* *}$ \\
Richness & & & & & \\
$\quad$ Total & $\mathbf{0 . 1 5}^{*}$ & $0.09 \dagger$ & $0.09 \dagger$ & $\mathbf{0 . 1 6}^{*}$ & $0.07 \dagger$ \\
$\quad$ Herbivore & $\mathbf{0 . 1 6} *$ & $0.07 \dagger$ & 0.07 & $0.10 \dagger$ & $0.10 \dagger$ \\
Omnivore & 0.04 & 0.06 & $0.09 \dagger$ & 0.04 & 0.04 \\
$\quad$ Predator & 0.00 & 0.01 & 0.02 & 0.05 & 0.04 \\
Abundance & & & & & \\
$\quad$ Total & $\mathbf{0 . 2 6}^{*}$ & $\mathbf{0 . 1 2} *$ & $0.08 \dagger$ & $0.09 \dagger$ & $\mathbf{0 . 4 3}^{* *}$ \\
$\quad$ Herbivore & $\mathbf{0 . 2 6}^{*}$ & $0.08 \dagger$ & 0.06 & $0.06 \dagger$ & $\mathbf{0 . 2 5}^{*}$ \\
$\quad$ Omnivore & 0.05 & 0.04 & 0.07 & 0.04 & $\mathbf{0 . 4 0}^{* *}$ \\
$\quad$ Predator & 0.00 & 0.02 & 0.02 & 0.07 & 0.06 \\
\hline
\end{tabular}

Notes: The calculation of broad-sense heritability $\left(H^{2}=V_{\mathrm{g}} / V_{\mathrm{t}}\right)$ is also equivalent to the proportion of the total variation within a habitat explained by plant genotype. Values in boldface type are significant at $P=0.05$.

$\dagger P<0.1 ; * P<0.05 ; * * P<0.01$

have been indirect. Predator abundance was positively correlated with both herbivore $\left(F_{1,795}=16.5, P<\right.$ $\left.0.001, R^{2}=0.03\right)$ and omnivore abundance $\left(F_{1,871}=\right.$ 21.9, $\left.P<0.001, R^{2}=0.31\right)$, and the genotype-byhabitat interaction disappeared once either herbivores $\left(\chi_{1}=1.4, P=0.12\right)$ or omnivores (genotype by habitat: $\left.\chi_{1}=0.5, P=0.24\right)$ were included as a covariate.

\section{Community heritabilities and the effects of herbivores on plant fitness}

We detected heritable variation in $O$. biennis for several arthropod community variables (Table 2). Broadsense heritability varied between 0 and $0.43(0.10 \pm$ 0.016 ; means $\pm 1 \mathrm{SE}$ ), with nearly a quarter of estimated heritabilities being statistically significant. This observed frequency of significant heritabilities is unlikely to have occurred by chance (binomial expansion test, $P<0.001$; Zar 1996). In a separate experiment to test for the fitness effects of the herbivore community, herbivores reduced lifetime fruit production by

TABLE 3. Percentage of variation explained by microhabitat and plant genotype for Simpson's diversity index, species richness, and abundance of arthropods on individual plants (means $\pm 1 \mathrm{SE})$.

\begin{tabular}{lcr}
\hline \hline \multicolumn{1}{c}{ Variable } & Microhabitat & Genotype \\
\hline Simpson's diversity index & $5.89 \pm 3.71$ & $13.62 \pm 7.63$ \\
Richness & & \\
$\quad$ Total & $4.60 \pm 2.54$ & $11.01 \pm 2.06$ \\
$\quad$ Herbivore & $6.48 \pm 3.84$ & $9.99 \pm 1.95$ \\
$\quad$ Omnivore & $4.61 \pm 1.79$ & $5.53 \pm 1.07$ \\
$\quad$ Predator & $2.44 \pm 0.71$ & $2.38 \pm 1.09$ \\
Abundance & & \\
$\quad$ Total & $9.89 \pm 3.29$ & $19.62 \pm 7.38$ \\
$\quad$ Herbivore & $9.79 \pm 4.09$ & $14.13 \pm 5.19$ \\
$\quad$ Omnivore & $7.37 \pm 3.15$ & $12.08 \pm 7.93$ \\
$\quad$ Predator & $3.61 \pm 1.71$ & $3.24 \pm 1.36$ \\
\hline
\end{tabular}

Note: Means $\pm 1 \mathrm{SE}$ were calculated from the variance explained in each of the five habitats for each variable (see Methods).
$13 \%$ compared to controls, where the herbivore community was excluded (control least squares mean $[1$ smean $]=30.2, \mathrm{SE}=1.37$; herbivore lsmean $=26.8$, $\left.\mathrm{SE}=1.40 ; F_{1,122}=6.4, P=0.014\right)$.

\section{Plant traits}

To examine the potential for genetically controlled plant traits to drive the observed arthropod community patterns, we focused on Simpson's diversity index, total species richness, and total abundance. We detected genetic variation for 13 of the 14 plant traits measured (Appendix C). Across the five habitats, the single most important trait that correlated with arthropod community composition was a genotype's flowering (bolting) frequency (Fig. 3A). Forty-two percent of plants flowered in 2002 while the rest overwintered as rosettes and flowered in 2003. Genetic correlations between flowering frequency and Simpson's diversity accounted for $37-66 \%$ of the variation across habitats (Fig. 3A), $64-90 \%$ of the variation in species richness (Fig. 3B), and $37-84 \%$ of the variation in total abundance (Fig. $3 \mathrm{C})$. This trait was likely an important determinant of community patterns because several arthropod species exclusively feed on the flowers and fruits of O. biennis, whereas few if any species are exclusively found on rosettes. A single genotype collected from Jokers Hill consistently bolted more frequently than other genotypes, but removal of this genotype rarely changed the qualitative or statistical significance of the correlations, although the strength (i.e., $R^{2}$ ) of the correlations did decrease.

Despite the importance of flowering frequency, prominent effects of plant genotype on the arthropod community occurred in the disturbed habitat (Table 2), where all plants flowered. When we considered traits only expressed by these flowering plants (see Methods), we found that arthropod diversity decreased ( $r_{\text {gen }}=$ $-0.63, P=0.015$, Fig. 4A; $r$ for phenotype $\left[r_{\text {phen }}\right]=$ $-0.41, P<0.001)$, while richness $\left(r_{\text {gen }}=0.47, P=\right.$ 
0.09, Fig. 4B; $\left.r_{\text {phen }}=0.23, P<0.002\right)$ and abundance $\left(r_{\text {gen }}=0.78, P=0.001\right.$, Fig. $4 \mathrm{C} ; r_{\text {phen }}=0.60, P<$ $0.001)$ increased with larger plant sizes, architectural complexity, and flowering date, which were summarized within a single principal component axis. The removal of the single genotype from Mississauga did not change the direction of the relationships (Fig. 4), although the strength of the correlations did decrease. The negative correlation with arthropod diversity remained significant ( $r_{\text {gen }}=-0.55, P=0.05$ ), but the positive correlation with arthropod abundance became marginally significant ( $r_{\text {gen }}=0.49, P=0.09$ ), and the correlation with richness showed no relationship.

Several measures of plant resistance were correlated with community variables (Appendix D). Growth of the generalist caterpillar Spodoptera exigua positively correlated with the richness $\left(r_{\text {phen }}=0.26, P<0.05\right)$ and abundance $\left(r_{\text {phen }}=0.33, P<0.01\right)$ of arthropods, suggesting that more resistant plants harbored fewer arthropod species as well as fewer individuals. In contrast, the amount of "early season" herbivory negatively correlated with both arthropod species richness $\left(r_{\text {phen }}=-0.23, P<0.001\right)$ and abundance $\left(r_{\text {phen }}=\right.$ $-0.26, P<0.001)$. This latter pattern is consistent with a community-wide effect of "early season" induced plant responses.

\section{DisCUSSION}

We found that phenotypic variation in O. biennis is a major factor affecting the diversity and structure of the large arthropod fauna associated with this plant. This conclusion follows from three key results. First, plant genotype-by-habitat interactions strongly affected several measures of community composition (Table 1). Second, the importance of plant genotype vs. environmental variation was scale dependent, with the effect of genotype being more important than environment over small spatial scales, but less important over larger spatial scales (Table 3). Third, genotype strongly affected herbivores and omnivores, while the effects on predators were comparatively weak and indirect (Fig. 2).

\section{Community-level effects of genetic variation}

Since Southwood's (1961) and Murdoch et al.'s (1972) seminal research, ecologists have recognized that variation between plant species, a basal resource in most food webs, is an important determinant of arthropod communities. More recently, studies have shown that intraspecific phenotypic variation, and particularly plant genotype, can affect the absolute and/ or relative abundance of individual herbivore species (Kinsman 1982, Maddox and Root 1987, 1990, Fritz and Price 1988, Fritz 1990) and predators (Fritz 1995, Stiling and Rossi 1996) within communities. Our results corroborate these earlier findings as the overall abundance and evenness of herbivores, omnivores, and predators were affected by genotypic variation in $O$. biennis. We also present the novel result that plant genotype affects not only the abundance, but also the diversity of a large arthropod fauna. Similar to our findings, arthropod richness and composition in diverse arthropod communities varies between hybrid types (Dungey et al. 2000, Wimp and Whitham 2001, Hochwender and Fritz 2004). Thus, it is clear that from the intra- to the interspecific level, genetic variation is an important factor shaping the diversity of higher trophic communities.

Plants are known to have specific defenses against herbivory, while traits that affect predators are considerably less common (Hare 2002). Consistent with this, our results show that genetic variation in plant resistance strongly affected herbivores and omnivores, whereas the effects on predators were relatively weak (Table 2; Appendix B). The influence of plant genetic variation on predators may typically be restricted to indirect interactions, where effects on predators appear to be mediated by direct impacts of plant resistance on the behavior and density of phytophagous insects (Fritz 1995). Our results support this idea, as the genotypeby-habitat interaction affecting predator abundance disappeared once either herbivore or omnivore abundance was included as a covariate.

\section{Scale-dependent effects}

We found that the relative importance of plant genotype vs. environment was scale-dependent in affecting arthropod communities on $O$. biennis, with plant genotype being more important than variation within habitats, but less important than variation between habitats. Although our selection of five disparate habitats (as opposed to five randomly chosen habitats) could inflate the importance of large-scale environmental variation relative to genetic variation, we propose that these patterns are real and provide some clarity to contradictory findings across past studies about the relative importance of these factors (e.g., Fritz and Price 1988, Stiling 1994). The majority of studies have examined environmental variation among common gardens in different habitats or sites separated by hundreds of meters to kilometers (Fritz 1990, Strauss 1990, Quiring and Butterworth 1994, Stiling 1994, Stiling and Rossi 1995, 1996, Rossi and Stiling 1998, Stiling and Bowdish 2000, Ylioja et al. 2000). Typically, these studies found that environmental factors explained more variation in arthropod abundance than plant genotype (Appendix E). A smaller number of studies have investigated environmental variation within habitats (Maddox and Root 1987, Fritz and Price 1988, Quiring and Butterworth 1994, Ylioja et al. 2000) and concluded that plant genotype is as important, or more so, than environmental variation. These past studies did not explicitly consider how spatial scale affected the magnitude of environmental variation, which is predicted to increase with distance between locations (Bell 1992). By calculating the $R^{2}$ values from available AN- 
OVA tables in the above studies, we found that the relative importance of plant genotype vs. environmental variation in determining arthropod abundance increased with decreasing spatial scale (Appendix E). This is consistent with our findings on arthropod communities, as well as the scale-dependent hypothesis (Menge and Olson 1990).

\section{Plant traits}

Genetic variation has been found for a variety of plant traits, including plant secondary compounds, trichomes, morphology, and phenology (Fritz and Simms 1992). Our results suggest that morphological (i.e., plant size and architecture) and phenological (bolting phenology, flowering date) traits may be more important than other resistance traits (e.g., chemical) in affecting arthropod community composition (Figs. 3 and 4; Appendix D) (Aide 1988, Marquis et al. 2001). Although few studies have attempted to identify plant traits responsible for arthropod community patterns, Fritz and Price (1988) found that plant size positively correlated with the densities of four herbivore species. Also, Pilson (2000) showed that genetic variation in flowering phenology of Helianthus annuus affected herbivory by a community of specialist seed-head herbivores. The importance of flowering phenology on arthropod communities may be a general phenomenon for herbaceous plants with an insect fauna that specializes on reproductive parts. Our general assays of resistance (i.e., bioassay caterpillar growth and "early season" herbivory) and a specific putative resistance trait (leaf toughness) were phenotypically correlated with richness and abundance (Appendix D), yet their strength tended to be weaker than correlations involving morphological and phenological traits. It is possible that morphological and phenological plant traits have stronger affects on communities as a whole, while some chemical or physical resistance traits maybe more directed at specific common insect species or suites of species. A forthcoming article will explore this topic further (M. T. J. Johnson and A. A. Agrawal, unpublished manuscript).

\section{Plant evolution, community change, and conservation genetics}

Whitham et al. (2003) recently proposed that arthropod community composition can change as a result of selection on plants. For this to occur, a plant population must contain heritable variation that affects arthropod community structure (Maddox and Root 1987, Fritz and Price 1988, Hochwender and Fritz 2004). Consistent with this idea, we found heritable variation in $O$. biennis for many arthropod community variables (Table 2), which suggests that the community composition can change as a result of evolution in O. biennis. However, our results indicate that the importance of evolutionary processes in shaping community-level patterns will depend on the environmental context. We found that the heritabilities of arthropod community traits varied substantially across our five habitats (Table 2 ). This result is not surprising as the expression of genetically based phenotypic traits has frequently been reported to be variable in different environments (Hoffman and Merilä 1999). For example, in a recent study using the plant Raphanus raphanistrum, we reported that the expression of heritable variation for several putative resistance traits depended on whether or not plants were exposed to herbivory (Agrawal et al. 2002). The variability observed in heritabilities in the present study can be explained by (1) variation in the expression of phenotypic traits in the different environments and/or (2) variation in the arthropod communities' response to plant phenotypes (even if the plant phenotypes are not altered in the different habitats). For the former, it has been shown that increased environmental variance and/or decreased additive genetic variance can reduce heritable variation (Hoffman and Merilä 1999). Indeed, we found that variance attributed to both genetic and environmental sources substantially differed among habitats. For the latter, different arthropod species in different habitats or species-by-environment interactions may influence the effect of plant traits on the arthropod communities. Although our current analysis cannot disentangle these possibilities, a forthcoming manuscript will address this issue.

What selective agent would cause a plant population to evolve in a way to affect these heritable community variables is unclear. One possibility is that members of the arthropod community themselves drive evolution by imposing selection on phenology (Aide 1988) and genetically variable resistance traits (Agrawal 1998, Agrawal et al. 2002). For example, we found that herbivores reduced lifetime fruit production, suggesting that these herbivores may impose natural selection on traits of $O$. biennis. If true, this effect could lead to a dynamic evolutionary feedback between the plant population and arthropod community composition, where evolutionary processes dictate community patterns (Johnson and Agrawal 2003).

Based on our results, we speculate that the conservation of genetic variation may be of critical importance for the maintenance of community interactions. Much emphasis has been placed on conserving genetic variation within single species to maintain the longterm viability of those species (Lande 1988). We have shown that different plant genotypes have varying impacts on higher trophic communities. Therefore, reductions in the genetic diversity within populations are likely to have immediate community-level consequences for many species (Bangert et al. 2004, Wimp et al. 2004).

\section{ACKNOWLEDGMENTS}

We thank R. Barrett, J. Chalmers, M. Fernandez, N. Griffiths, B. Hall, J. Jensen, J. Kung, N. Kurashige, N. Ledra, A. Pietri, L. Plane, R. McGuire, C. Muis, A. Plattner, M. Stewart, J. Toffoli, P. Van Zandt, and D. Viswanathan for logistical 
support, W. Wagner for identifying Oenothera specimens, and G. Scudder and M. Schwartz for identifying the Hemiptera. T. Ylioja kindly made data available for the review of $G \times$ E studies. The Koffler family generously donated Jokers Hill to U. of T. Advice and support were given by S. Barrett, C. Brassil, T. Carleton, M. Eubanks, C. Fox, R. Johnson, R. Karban, M. Lajeunesse, C. Rodriguez-Saona, M. Saunders, J. Thaler, and anonymous reviewers. Our research is funded by Sigma Xi, Mountain Equipment Co-op Environment Fund, and the Natural Sciences and Engineering Research Council of Canada.

\section{LiterATURE CiTED}

Agrawal, A. A. 1998. Induced responses to herbivory and increased plant performance. Science 279:1201-1202.

Agrawal, A. A. 2002. Herbivory and maternal effects: mechanisms and consequences of transgenerational induced plant resistance. Ecology 83:3408-3415.

Agrawal, A. A., J. K. Conner, M. T. J. Johnson, and R. Wallsgrove. 2002. Ecological genetics of an induced plant defense against herbivores: additive genetic variance and costs of phenotypic plasticity. Evolution 56:2206-2213.

Aide, T. M. 1988. Herbivory as a selective agent on the timing of leaf production in a tropical understory community. Nature 336:574-575.

Andrewartha, H. G., and L. C. Birch. 1954. The distribution and abundance of animals. University of Chicago Press, Chicago, Illinois, USA.

Antonovics, J. 1992. Toward community genetics. Pages 426-449 in R. S. Fritz and E. L. Simms, editors. Plant resistance to herbivores and pathogens: ecology, evolution, and genetics. University of Chicago Press, Chicago, Illinois, USA.

Bangert, R. K., R. J. Turek, G. D. Martinsen, G. M. Wimp, J. K. Bailey, and T. G. Whitham. 2004. Benefits of conservation of plant genetic diversity on arthropod diversity. Conservation Biology, in press.

Bell, G. 1992. Five properties of environments. Pages 3356 in P. R. Grant and H. S. Horn, editors. Molds, molecules, and metazoa: growing points in evolutionary biology. Princeton University Press, Princeton, New Jersey, USA.

Cleland, R. E. 1972. Oenothera: cytogenetics and evolution. First edition. Academic Press, New York, New York, USA.

Da Costa, C. P., and C. M. Jones. 1971. Cucumber beetle resistance and mite susceptibility controlled by bitter gene in Cucumis sativus L. Science 172:1145-1146.

Dickerson, E. L., and H. B. Weiss. 1920. The insects of the evening primroses in New Jersey. Journal of New York Entomological Society 28:32-74.

Dungey, H. S., B. M. Potts, T. G. Whitham, and H. F. Li. 2000. Plant genetics affects arthropod community richness and composition: evidence from a synthetic eucalypt hybrid population. Evolution 54:1938-1946.

Farrell. 1998. "Inordinate fondness" explained: why are there so many beetles? Science 281:555-559.

Fritz, R. S. 1990. Effects of genetic and environmental variation on resistance of willow to sawflies. Oecologia 82: 325-332.

Fritz, R. S. 1992. Community structure and species interactions of phytophagous insects on resistant and susceptible host plants. Pages 240-277 in R. S. Fritz and E. L. Simms, editors. Plant resistance to herbivores and pathogens: ecology, evolution, and genetics. University of Chicago Press, Chicago, Illinois, USA.

Fritz, R. S. 1995. Direct and indirect effects of plant genetic variation on enemy impact. Ecological Entomology 20:1826.

Fritz, R. S., C. G. Hockwender, S. J. Brunsfeld, and B. M. Roche. 2003. Genetic architecture of susceptibility to herbivores in hybrid willows. Journal of Evolutionary Biology 16:1115-1126.
Fritz, R. S., and P. W. Price. 1988. Genetic variation among plants and insect community structure: willows and sawflies. Ecology 69:845-856.

Fritz, R. S., and E. L. Simms, editors. 1992. Plant resistance to herbivores and pathogens: ecology, evolution, and genetics. University of Chicago Press, Chicago, Illinois, USA.

Gross, K. L., and M. L. Kromer. 1986. Seed weight effects on growth and reproduction in Oenothera biennis L. Bulletin of the Torrey Botanical Club 113:252-258.

Hare, D. J. 2002. Plant genetic variation in tritrophic interactions. Pages 8-43 in T. Tscharntke and B. A. Hawkins, editors. Multitrophic level interactions. Cambridge University Press, Cambridge, UK.

Hochwender, C. G., and R. S. Fritz. 2004. Plant genetic differences influence herbivore community structure: evidence from a hybrid willow system. Oecologia 138:547557.

Hoffmann, A. A., and J. Merilä. 1999. Heritable variation and evolution under favourable and unfavourable conditions. Trends in Ecology and Evolution 14:96-101.

Jackson, D. A., P. R. Peres-Neto, and J. D. Olden. 2001. What controls who is where in freshwater fish communities: the roles of biotic, abiotic, and spatial factors. Canadian Journal of Fisheries and Aquatic Sciences 58:157-170.

Johnson, M. T. J., and A. A. Agrawal. 2003. The ecological play of predator-prey dynamics in an evolutionary theatre. Trends in Ecology and Evolution 18:549-551.

Karban, R. 1992. Plant variation: its effects on populations of herbivorous insects. Pages 195-215 in R. S. Fritz and E. L. Simms, editors. Plant resistance to herbivores and pathogens: ecology, evolution, and genetics. University of Chicago Press, Chicago, Illinois, USA.

Kinsman, S. 1982. Herbivore responses to Oenoethera biennis (Onagraceae): effects of the host plant's size, genotype, and resistance of conspecific neighbors. Dissertation. Cornell University, Ithaca, New York, USA.

Lande, R. 1988. Genetics and demography in biological conservation. Science 241:1455-1460.

Levin, D. A. 1975. Genic heterozygosity and protein polymorphism among local populations of Oenothera biennis. Genetics 79:477-491.

Littell, R. C., G. A. Milliken, W. W. Stroup, and R. D. Wolfinger. 1996. SAS system for mixed models. SAS Institute, Cary, North Carolina, USA.

Lynch, M., and B. Walsh. 1998. Genetics and analysis of quantitative traits. Sinauer, Sunderland, Massachusetts, USA.

Maddox, G. D., and N. Cappuccino. 1986. Genetic determination of plant susceptibility to an herbivorous insect depends on environmental context. Evolution 40:863-866.

Maddox, G. D., and R. B. Root. 1987. Resistance to 16 diverse species of herbivorous insects within a population of goldenrod, Solidago altissima: genetic variation and heritability. Oecologia 72:8-14.

Maddox, G. D., and R. B. Root. 1990. Structure of the encounter between goldenrod (Solidago altissima) and its diverse insect fauna. Ecology 71:2115-2124.

Marquis, R. J., I. R. Diniz, and H. C. Morais. 2001. Patterns and correlates of interspecific variation in foliar insect herbivory and pathogen attach in Brazilian cerrado. Journal of Tropical Ecology 17:127-148.

Menge, B. A., and A. M. Olson. 1990. Role of scale and environmental factors in regulation of community structure. Trends in Ecology and Evolution 5:52-57.

Murdoch, W. W., F. C. Evans, and C. H. Peterson. 1972. Diversity and pattern in plants and insects. Ecology 53: 819-829.

Neuhauser, C., D. A. Andow, G. E. Heimpel, G. May, R. G. Shaw, and S. Wagenius. 2003. Community genetics: ex- 
panding the synthesis of ecology and genetics. Ecology 84 545-558.

Pilson, D. 2000. Herbivory and natural selection on flowering phenology in wild sunflower, Helianthus annuus. Oecologia 122:72-82.

Quiring, D. T., and E. W. Butterworth. 1994. Genotype and environment interact to influence acceptability and suitability of white spruce for a specialist herbivore, Zeiraphera canadensis. Ecological Entomology 19:230-238.

Rossi, A. M., and P. Stiling. 1998. The interactions of plant clone and abiotic factors on a gall-making midge. Oecologia 116:170-176.

Rudgers, J. A. 2004. Enemies of herbivores can shape plant traits: selection in a facultative ant-plant mutualism. Ecology 85:192-205.

Shaw, R. G., G. A. J. Platenkamp, F. H. Shaw, and R. H. Podolsky. 1995. Quantitative genetics of response to competitors in Nemophtla menziesii: a field experiment. Genetics 139:397-406.

Smith, B., and J. B. Wilson. 1996. A consumer's guide to evenness indices. Oikos 76:70-82.

Southwood, T. R. E. 1961. The number of species of insect associated with various trees. Journal of Animal Ecology 30: $1-8$.

Stiling, P. 1994. Coastal insect herbivore populations are strongly influenced by environmental variation. Ecological Entomology 19:39-44.

Stiling, P., and T. I. Bowdish. 2000. Direct and indirect effects of plant clone and local environment on herbivore abundance. Ecology 81:281-285.

Stiling, P., and A. M. Rossi. 1995. Coastal insect herbivore communities are affected more by local environmental conditions than by plant genotype. Ecological Entomology 20: 184-190.

Stiling, P., and A. M. Rossi. 1996. Complex effects of genotype and environment on insect herbivores and their enemies. Ecology 77:2212-2218.
Stratton, D. A., and C. C. Bennington. 1998. Fine-grained spatial and temporal variation in selection does not maintain genetic variation in Erigeron annuus. Evolution 52: 678-691.

Strauss, S. Y. 1990. The role of plant genotype, environment and gender in resistance to a specialist Chrysomelid herbivore. Oecologia 84:111-116.

Tabachnick, B. G., and L. S. Fidell. 2001. Using multivariate statistics. Fourth edition. Allyn and Bacon, Meedham Heights, Maine, USA

Thomas, S. C., and F. A. Bazzaz. 1993. The genetic component in plant size hierarchies: norms of reaction to density in a Polygonum species. Ecological Monographs 63: 231-249.

Underwood, N., and M. D. Rausher. 2000. The effects of host-plant genotype on herbivore population dynamics. Ecology 81:1565-1576.

Vinson, S. B. 1999. Parasitoid manipulation as a plant defense strategy. Annals of the Entomological Society of America 92:812-828.

Whitham, T. G., W. P. Young, G. D. Martinsen, C. A. Gehring, J. A. Schweitzer, S. M. Shuster, G. M. Wimp, D. G. Fischer, J. K. Bailey, R. L. Lindroth, S. Woolbright, and C. R. Kuske. 2003. Community and ecosystem genetics: a consequence of the extended phenotype. Ecology 84:559-573.

Wimp, G. M., and T. G. Whitham. 2001. Biodiversity consequences of predation and host plant hybridization on an aphid-ant mutualism. Ecology 82:440-452.

Wimp, G. M., W. P. Young, S. A. Woolbright, G. D. Martinsen, P. Keim, and T. G. Whitham. 2004. Conserving plant genetic diversity for dependent animal communities. Ecology Letters 7:776-780.

Ylioja, T., H. Roininen, J. Heinonen, and M. Rousi. 2000. Susceptibility of Betula pendula clones to Phytobia betulae, a dipteran miner of birch stems. Canadian Journal of Forest Research 30:1824-1829.

Zar, J. H. 1996. Biostatistical analysis. Prentice Hall, Upper Saddle River, New Jersey, USA.

\section{APPENDIX A}

A table presenting genotype by environment crossover interactions is available in ESA's Electronic Data Archive: Ecological Archives E086-046-A1.

\section{APPENDIX B}

A table presenting genotypic and environmental effects on richness and abundance of herbivores, omnivores, and predators is available in ESA's Electronic Data Archive: Ecological Archives E086-046-A2.

\section{APPENDIX C}

A table presenting genetic and environmental effects on 14 plant traits is available in ESA's Electronic Data Archive: Ecological Archives E086-046-A3.

\section{APPENDIX D}

A table presenting phenotypic and genetic correlations of plant traits vs. Simpson's diversity index, richness, and abundance of arthropods is available in ESA's Electronic Data Archive: Ecological Archives E086-046-A4.

\section{APPENDIX E}

A review of common-garden studies examining the manner in which arthropod abundance and density are affected by plant genotype, environment, and their interaction at multiple spatial scales is available in ESA's Electronic Data Archive: Ecological Archives E086-046-A5. 